\title{
The effects of concentration of cutting fluids on machining performance during end milling of steel St60
}

\author{
Yousef Shokoohi ${ }^{1}$, Ehsan Khosrojerdi ${ }^{1}$ And Ehsan SheKarian ${ }^{2}$, a \\ 1 Faculty of mechanical engineering, Babol Noshirvani University of Technology, Babol, Iran \\ 2 Department of Chemical Engineering, College of Engineering, Azadshahr Branch, Islamic Azad University, Azadshahr, Iran
}

Received 12 August 2014, Accepted 21 September 2015

\begin{abstract}
Lubrication plays an important role in increasing efficiency of a machining operation when high temperature and friction are two major issues. In the current study, two various types of lubricant SAE10 oil and vegetable oil were tested in end milling of a steel St60 block and the results were compared with dry condition. To have a clear understanding of the lubrication effects, three different concentrations for each lubricant using proper solvent were made and surface roughness (Ra), machining power and tool wear were compared in three distinct machining conditions. These conditions differ in depth of cut and machining speed (in a constant feed rate) according to real application. Among the lubrication environments, SAE10 assisted machining in low spindle speed showed better results. Moreover, it was observed that dry machining and machining in presence of vegetable oil especially in the cases of cutting fluids with lower oil content in fairly high tool velocity lead to process productivity improvement. Finally, dry machining resulted in more wear on cutting tool.
\end{abstract}

Key words: Cutting fluid / oil concentration / machining power / surface roughness / tool wear / milling

\section{Introduction}

For as long as people cut metals, they have utilized a fluid to aid the process. May be water was the first fluid used, followed by animal fats, vegetable oils, mineral oil, etc. [1]. The main goal in manufacturing is to minimize production time, cost, energy and resources while maintaining or even improving performance [2]. By this way metal cutting fluids are important. Fluids provide a lubricated layer between the tool-workpiece adjacent surfaces and help to reduce interfacial friction [3]. Cooling feature of a fluid could help to decrease undesirable and uncontrollable workpiece, tool and chip temperature [4]. In addition, due to intrinsic mobility feature, fluids could flush away the produced chips during machining [5]. Metal working fluid has some main roles; such as:

- Transportation of the chip.

- Rewelding arrest.

- Corrosion protection.

- Power reduction.

- Tool life extension and productivity increasing.

- Creation of a certain type of chip.

\footnotetext{
${ }^{a}$ Corresponding author: Ehsan.Shekarian@gmail.com
}

- Cooling.

- Lubrication [1].

There are several researches dealt with the effects of different lubrication environment [6-8], fluid concentration $[9,10]$ and viscosity [11] on lubrication performance and machining efficiency. Krishna and Rao [9] evaluated the performance of solid lubrication in turning EN8 steel. They used SAE 40 as the base oil and mixed it with two solid lubricant graphite and boric acid in five proportions ranged from 5 to $40 \%$ by weight. Results of cutting forces, tool wear, tool temperature and surface roughness were compared with wet and dry conditions. They revealed that by increasing the ratio of solid content, the kinematic viscosity increased but the results did not show a specific trend toward these changes. A low and a moderate viscosity depicted a better performance for graphite and boric acid lubrication assisted machining, respectively.

Vegetable oils demonstrated to be as a potential source of environmentally favorable lubricants, due to a combination of biodegradability, renewability and excellent lubrication performance [12]. These oils, refering to [13] are nontoxic to the environment and biologically inert and do not produce significant organic disease and toxic effect. 
There are several researchers dealing with use of vegetable oils in machining operations $[3,10,11,14,15]$. Vasu and Reddy [10] studied the effect of $\mathrm{Al}_{2} \mathrm{O}_{3}$ nanoparticles in two concentrations in vegetable based oils. The observations showed that surface finish and temperature dissipation of the workpiece raised with different volume fractions of $\mathrm{Al}_{2} \mathrm{O}_{3}$ nanoparticle addition. It is also possible to observe a decrease in cutting forces and tool wear rate and a reduction in the negative environmental effects, owing to $\mathrm{Al}_{2} \mathrm{O}_{3}$ nanoparticle addition to MQL in machining. For example reduction in surface roughness values when using $\mathrm{MQL}+6 \% \mathrm{Al}_{2} \mathrm{O}_{3}$ nanofluid compared with MQL and MQL $+4 \% \mathrm{Al}_{2} \mathrm{O}_{3}$ nanofluids was observed. Gunerkar and Kuppan [11] formulated two different vegetable based cutting fluids; rapeseed oil and sunflower oil in form of emulsion. A variety of nonionic surfactants were used in turning SS316L. They investigated the fluids with different viscosities. In the sunflower based oil emulsion, tool wear was considerably less compared to soluble oil emulsion. Siniawski et al. [14] investigated the tribological characteristics of soybean and sunflower vegetable oils in comparison with a base mineral oil. A $440{ }^{\circ} \mathrm{C}$ stainless steel ball-on-disc test was conducted for each lubricant. The vegetable-based lubricants make up the lower abrasion rate and friction coefficient when compared to the mineral oil. With determination of fatty acid compositions, the authors proposed that the lower abrasion rate and coefficient of friction for the soybean oil are attributed to its smaller percentages of linoleic oleic acids. Cetin [15] evaluated the vegetable based cutting fluids with extreme pressure in turning AISI 304L. They investigated the function of extreme pressure (EP) and different surfactants in surface roughness, cutting and feed forces. They illustrate that viscosity of a cutting fluid is one of the parameters determining the effectiveness of cutting fluids. Results show CCF-II (canola based cutting fluids) and SCF-I (sunflower based cutting fluids) for surface roughness, SCF-II and CCF-II for cutting forces. CCFII and SCF-II for feed forces show greater performances than CMCF (commercial mineral based cutting fluid) and CSSCF (commercial semi-synthetic cutting fluid). Higher rate of EP in cutting fluids gives better machining performance for decreasing cutting and feed forces. However, it affects surface roughness values negatively due to chemical interaction with the machined surface. According to Kuram et al., the EP additive concentration is critical because the reaction with the metallic surfaces is a form of mild corrosion [16].

In this study the effect of different cutting fluids on end milling performance of St60 steel will be investigated. The aim is to make diverse lubrication conditions out of two primary vegetable-based and chemical-based oils by utilizing a suitable solvent namely n-Hexane. Different provided concentrations of oils allow to precisely analyse the effects of concentration of cutting fluids on the quality of machining. Furthermore milling in dry condition is included in the study to make a better comparison. Applying these lubrication conditions on three real combinations of cutting speed and depth of cut besides the dry milling which assembles various machining conditions is the outstanding features of this study.

\section{Experimental procedure}

\subsection{Lubrication}

Two oils namely sunflower oil and SAE10 oil are used as basic substances of different vegetable-based and chemical-based cutting fluids with various concentrations. The vegetable oil includes $7 \%$ linoleic acid, $1 \%$ erucic acid and no fatty acid content. The concentrations of the oils were decreased by using n-Hexane solvent. This solvent has reasonable price and good solvency blends easily with oil, makes a steady solution and does not make any foam. The cutting fluids are made in three concentration levels with proportion of solvent to oil 1:20, 5:20 and 9:20. These combinations of lubricants were set based on some preliminary tests. Refering to Sharma et al. [17] the lubricating and cooling features of cutting fluids have a dominant role on the cutting quality at low and high cutting speeds, respectively. So the objective was to keep the fluid mixture inside a reasonable range by changing the solvent content.

To do lubrication action, fluids are carried to the cutting zone by using a small centrifugal pump. The nozzle tip is positioned just in front of the cutting tool movement. The nozzle is fixed in a proper position refer to Yan et al. [18]. They suggested setting relative nozzle feed position at $120^{\circ}$, angle elevation of $60^{\circ}$ and nozzle tip distance from cutting zone at $20 \mathrm{~mm}$. Machining is then performed to evaluate the effects of concentration and lubrication types on surface quality of machined zone and machining power as well as tool wear.

\subsection{Cutting elements}

Experiments are carried out in a FP4M Machine Sazi Tabriz universal milling machine. For any lubrication state, an HSS end mill tool with four flutes is mounted onto the spindle chuck and the tests are done. Machining operation is performed on a structural steel block namely St60. It is used extensively for making riveting, bolting, welding and any purpose needs good welding properties and guaranteed strengths. The steel is supplied in hardness range of about $3-34 \mathrm{HRc}$ with tensile strength between 590 and $770 \mathrm{MPa}$.

\subsection{Milling condition}

Two machining stages were considered in this work. According to real application, the first stage is comprised of different combinations of tool velocity and depth of cut in a constant tool feed rate. Three states of machining are chosen as following:

I. Low velocity and high depth of cut.

II. Medium velocity and low depth of cut.

III. High velocity and low depth of cut. 


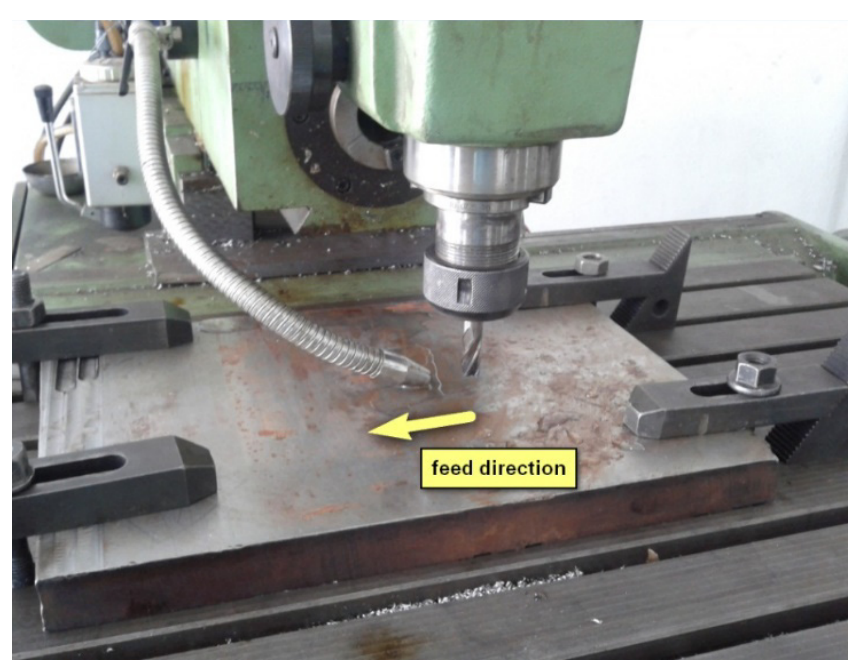

Fig. 1. Machining set up: workpiece clamping and nozzle tip position.

After making the experimental setup and clamping the workpiece (Fig. 1), the machining is done through different paths with specified cutting length for all milling and lubrication conditions.

To obtain reliable information, each experiment was repeated three times and an average of $\mathrm{Ra}$ and power index was reported. The concentrations which result in the best surface roughness are selected as the cutting fluids to be used in the second machining stage which is done in about $15 \mathrm{~min}$. This stage is planned to reveal the effect of cutting fluids on tool wear.

Details of experimental conditions are shown in Table 1.

\subsection{Measuring devices}

A Marsurf-Ps1 at $10 \mathrm{~mm}$ cut-off value from four different positions and a Lutron ammeter were utilized to measure surface roughness and electrical current, respectively. The relation between electrical current and power in three- phase induction motor is:

$$
P=\sqrt{3} V I \cos (\varphi)
$$

where $V$ is Inner Voltage $(\mathrm{V}), I$ shows electrical current (A) and $\operatorname{Cos}(\varphi)$ is power factor (in this work P.F is about 0.79 , measured by HIOKI Cos $(\varphi)$ meter). Since $V$ and $\operatorname{Cos}(\varphi)$ are constant in all states in this work, electrical current is presented as the index of power consumption.

Scanning electron microscope (SEM) was employed to observe the wear on the cutting tools. To show the tool wear, SEM images were taken from the bottom view of tools as shown in (Fig. 2).

\section{Results and discussion}

The influences of lubrication on surface roughness, machining power and tool wear will be discussed. Table 2

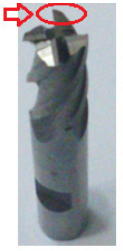

(a)

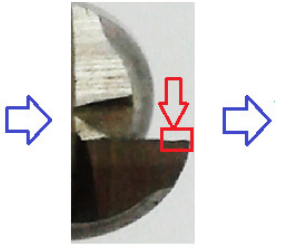

(b)

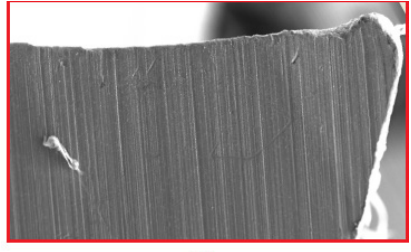

(c)
Fig. 2. Cutter edge selection for taking SEM images from the worn tool to indicate amount of flank wear:(a) end mill tool, (b) bottom view of the tool and (c) a SEM image sample.

illustrates the data for surface roughness and machining power.

Assessment of various lubrication conditions is shown in the following bar chart figures and the average effects of the fluids are represented with dashed line. Additionally, the machining fluids were distinguished with their concentrations so that the first level corresponds to the highest concentration of oil (1:20). To figure out the values of the levels, dynamic viscosity of the fluids was measured with viscometer and the results are shown in Table 3.

\subsection{Surface roughness}

One of the major factors that influence the workpiece quality of the machined parts is surface roughness. Surface quality affects the functional characteristics of the workpiece such as compatibility, fatigue resistance and surface friction. The factors which influence the surface roughness during the end milling process, include tool geometry, process parameters and heat generated in machining operation [3]. Figure 3 shows surface finish values in a hard machining situation where there is a combination of low tool velocity (V) and high depth of cut (DOC). Different responses from variation in lubrication and cooling characteristic of the cutting fluids were observed.

SAE10 oils especially in lower concentrations, show better results compared with the vegetable oil and dry cutting. For SAE10 oil, a significant drop in surface roughness is visible as the concentration decreases, owing to low viscosity. In low cutting speeds, fluid has enough time to penetrate into tool-workpiece interface and could make a cushion to avoid direct metal to metal contact. This lowers the frictional forces and helps improvement of surface finish. Poor surface roughness resulted from the first concentration of SAE10 oil could be interpreted as its high viscosity which impairs the penetration ability especially in high depth of cuts. In the case of vegetable based fluids, second level brings about better finished surface. Suitable composition of oil and solvent gives good heat transfer ability and proper viscosity to the fluid to penetrate easily into the cutting zone. It should be noted that produced heat during machining negatively effects the surface quality of final workpiece in the form of metallurgical transformations, oxidation, etc. [19]

In higher cutting speeds, penetration of fluids into the cutting zone is reduced and so impairs their lubrication action. Moreover, because of higher chip removal rate, 
Y. Shokoohi et al.: Mechanics \& Industry 17, 407 (2016)

Table 1. End milling conditions.

\begin{tabular}{|c|c|}
\hline \multicolumn{2}{|c|}{ Machine tool } \\
\hline Type & Vertical milling machine \\
\hline \multicolumn{2}{|c|}{ Cutting tool } \\
\hline Type & End mill \\
\hline Material & HSS \\
\hline Diameter (mm) & 10 \\
\hline Number of flutes & 4 \\
\hline Nose radius (mm) & 0.4 \\
\hline \multicolumn{2}{|c|}{ Workpiece } \\
\hline Material & St60 \\
\hline Hardness & $30-34 \mathrm{RC}$ \\
\hline \multicolumn{2}{|c|}{ Milling parameters: First stage } \\
\hline Velocity (rpm) & 315(Low),710(Medium), 1250 (High) \\
\hline Depth of cut (DOC) (mm) & 1 (Low), 2 (High) \\
\hline Feed rate $(\mathrm{mm} / \mathrm{min})$ & 50 \\
\hline Length of cut (mm) & 150 \\
\hline \multicolumn{2}{|c|}{ Milling parameters: Second stage } \\
\hline Velocity (rpm) & 710 \\
\hline Depth of cut (DOC) (mm) & 1 \\
\hline Feed rate $(\mathrm{mm} / \mathrm{min})$ & 50 \\
\hline Time of machining (min) & 15 \\
\hline \multicolumn{2}{|c|}{ Lubrication } \\
\hline Environment & Dry and wet \\
\hline Cutting oil & Sunflower oil, SAE10 oil \\
\hline Position of nozzle tip & \\
\hline With respect to the tool & In front \\
\hline With respect to the front workpiece surface & $60^{\circ}$ \\
\hline Distance to the tool (mm) & 20 \\
\hline
\end{tabular}

Table 2. Surface roughness and electrical current consumption.

\begin{tabular}{|c|c|c|c|c|c|c|c|}
\hline \multirow{2}{*}{ Machining Fluids } & \multirow{2}{*}{ level } & \multicolumn{2}{|c|}{ Machining state \# I } & \multicolumn{2}{|c|}{ Machining state \# II } & \multicolumn{2}{|c|}{ Machining state \# III } \\
\hline & & $R a^{*}$ & $I^{* *}$ & $R a$ & $I$ & $R a$ & $I$ \\
\hline \multirow{3}{*}{ SAE10 oil } & 1 & 3.76 & 3.11 & 3.4 & 3.14 & 2.28 & 3.15 \\
\hline & 2 & 1.52 & 3.01 & 2.95 & 3.07 & 1.95 & 3.08 \\
\hline & 3 & 1.72 & 3.04 & 3.15 & 3.06 & 2.12 & 3.10 \\
\hline \multirow{3}{*}{ Vegetable oil } & 1 & 5.4 & 3.05 & 2.18 & 3.09 & 1.64 & 3.10 \\
\hline & 2 & 4.62 & 3.02 & 2.13 & 3.04 & 2.03 & 3.04 \\
\hline & 3 & 4.81 & 2.94 & 2.15 & 3.03 & 1.52 & 2.99 \\
\hline Dry & - & 4.96 & 2.97 & 2.82 & 3.06 & 1.35 & 3.09 \\
\hline
\end{tabular}

* $R a$ in $(\mu \mathrm{m}),{ }^{* *} I$ in $(\mathrm{A})$.

\section{Surface roughness $(\mu \mathrm{m})$}

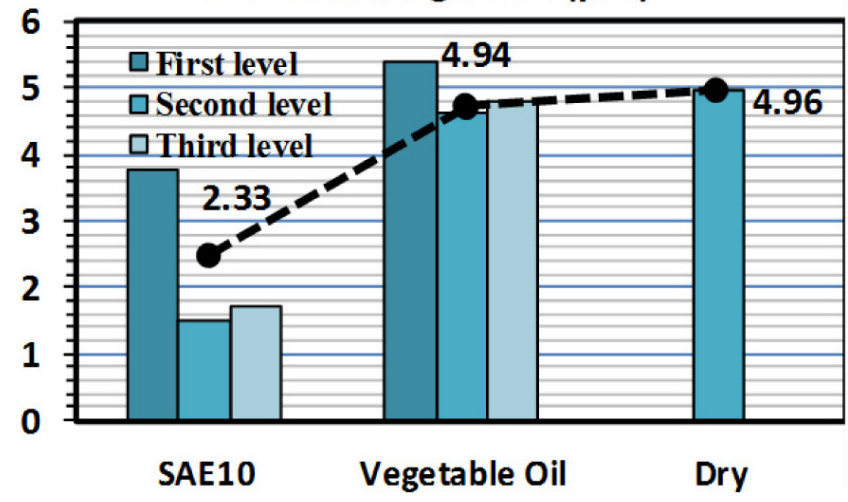

Fig. 3. Effect of concentration of different lubricants on surface roughness: $V=315 \mathrm{rpm}, D O C=2 \mathrm{~mm}$.
Table 3. Dynamic viscosity values of fluids in temperature of $40{ }^{\circ} \mathrm{C}$.

\begin{tabular}{ccc}
\hline Fluid & Level & Viscosity (cSt) \\
\hline \multirow{3}{*}{ SAE10 oil } & 1 & 30 \\
& 2 & 22 \\
& 3 & 16 \\
\hline \multirow{3}{*}{ Vegetable oil } & 1 & 23 \\
& 2 & 14 \\
& 3 & 10 \\
\hline
\end{tabular}

cutting zone temperature rises. In such a condition the cooling action becomes a predominant feature of cutting fluid in improvement of machinability [17]. As Figures 4 and 5 depict, almost none of the coolants could penetrate in the tool-workpiece interface. Inconsiderable differences 


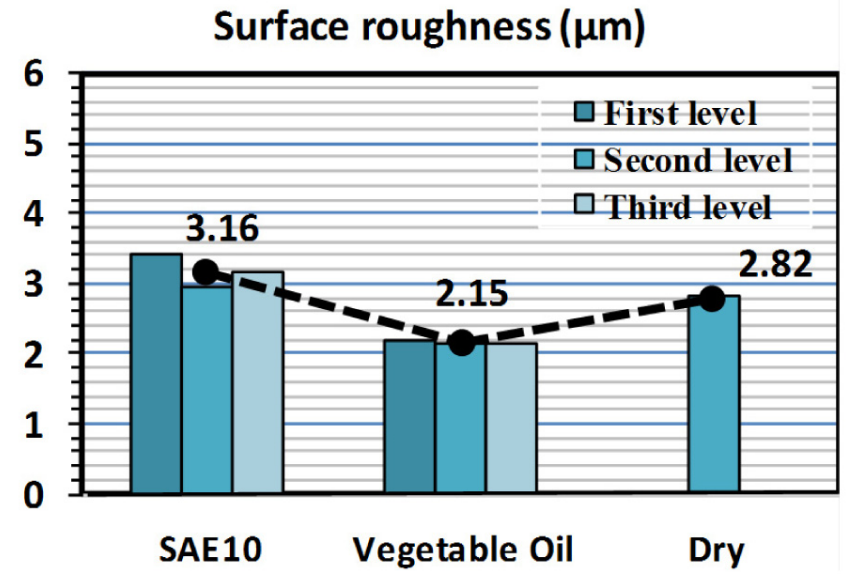

Fig. 4. Effect of concentration of different lubricants on surface roughness: $V=710 \mathrm{rpm}, D O C=1 \mathrm{~mm}$.

\section{Surface roughness $(\mu \mathrm{m})$}

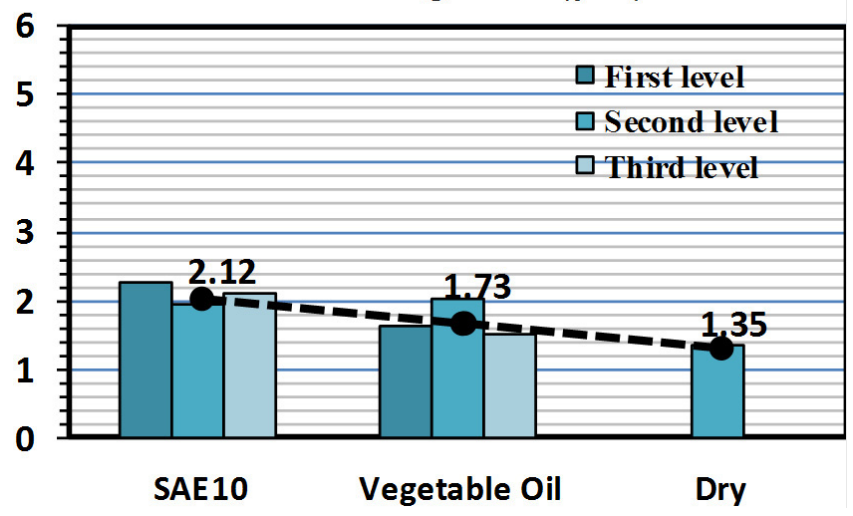

Fig. 5. Effect of concentration of different lubricants on surface roughness: $V=1250 \mathrm{rpm}, D O C=1 \mathrm{~mm}$.

in surface roughness values produced in machining with all lubrication environments in the third machining condition support the above fact. Although, in the second machining state, vegetable based cutting oil resulted in better surface finish compared with SAE10 oil. This is caused by lower viscosity and higher heat transfer coefficient of vegetable oil which better its penetration ability and lower cutting temperature, respectively. Refering to [19] fluids with low viscosity show better heat transfer ability and better penetration into tool-workpiece interface which efficiently decrease cutting temperature.

Furthermore, dry machining also results acceptable surface finish. Depletion in surface roughness may refer to increase in workpiece temperature up to a particular level which softens the material and decreases undesirable vibrations caused by cutting forces. Cutting temperature increases with the rise in machining speed from 710 to $1250 \mathrm{rpm}$. In the higher speed, the best surface quality is the result of dry machining (Fig. 5). Vegetable oil and SAE10 oil followed the dry cutting, respectively.
Electrical current $(A)$

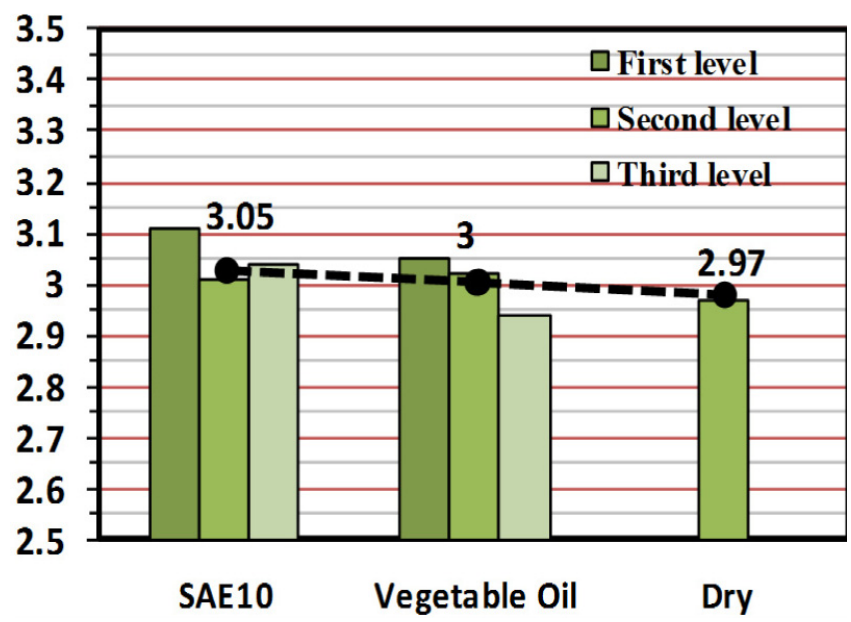

Fig. 6. Effect of concentration of different lubricants on Power consumption index: $V=315 \mathrm{rpm}, D O C=2 \mathrm{~mm}$.

\subsection{Machining power}

The power consumed by machine tool in removing excess material from the workpiece is an important parameter in evaluating economical aspect and production efficiency of machining. In machining operation this factor could be dependent on some agents such as: (1) machining condition (depth of cut, feed rate and cutting speed) (2) metalworking fluids due to their direct effects on frictional forces, generated heat and final machining temperature and (3) tool wear that could change tool geometry which alters contact surface between tool and workpiece.

As depicted in the Figures 6 to 8, all the three combinations of cutting speed and depth of cut exhibit almost a same trend. The results reveal that changes in lubrication condition could affect the machining power. Almost in all cases, machining in dry condition resulted in low milling power. This may be because of difference in final work material temperature. In absence of coolant, generated heat decreases material shear strength and provides an easy situation for chip removal. This could lower the resistant forces and so decreases the machine tool power consumption. Ginta and his colleagues emphasized this fact that an increase in temperature gives depletion in cutting force [20]. Vegetable and SAE10 oils due to good lubrication characteristic reduce frictional forces and as a result lower milling power. The results generally illustrate better cutting performance in dry machining and applying cutting oils in lower concentration.

\subsection{Tool wear}

To make an accurate decision on the effect of cutting fluids on machining performance, as well as the surface finish and machining power it is important to investigate the cutting tool failure. Tool wear describes the 


\section{Electrical current (A)}

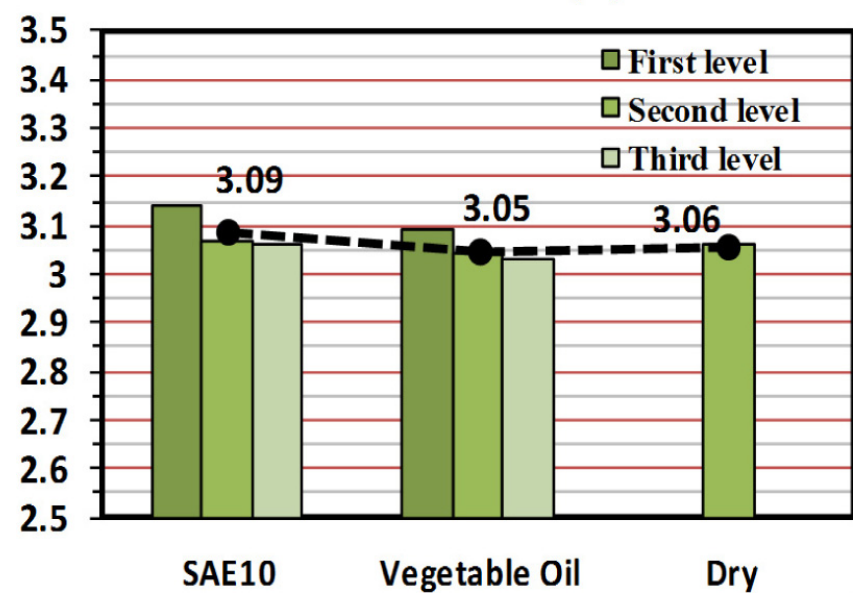

Fig. 7. Effect of concentration of different lubricants on Power consumption index: $V=710 \mathrm{rpm}, D O C=1 \mathrm{~mm}$.

\section{Electrical current (A)}

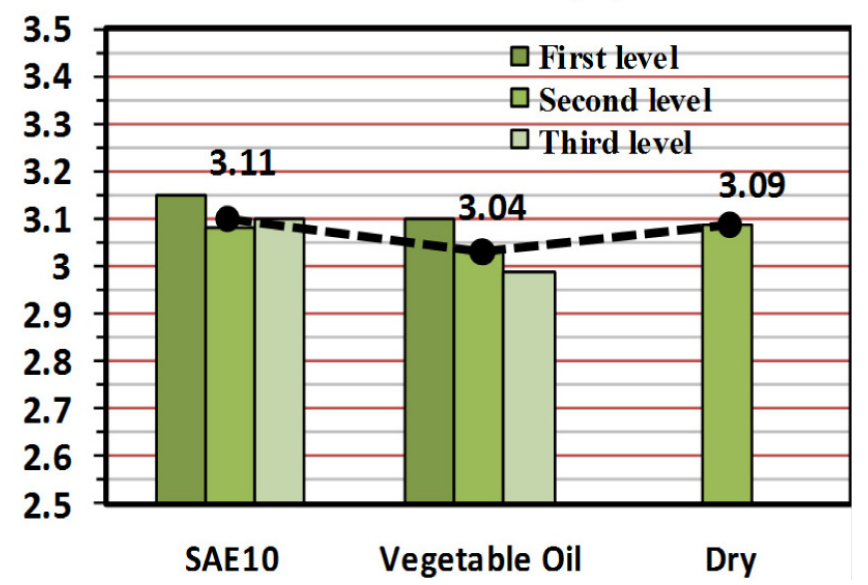

Fig. 8. Effect of concentration of different lubricants on Power consumption index: $V=1250 \mathrm{rpm}, D O C=1 \mathrm{~mm}$.

gradual failure of cutting tools during a metal cutting operation. Friction and wear of cutting tools often detrimentally limit the performance of cutting processes [21]. Several reasons cause tool wear; the most significant ones are: abrasion, adhesion and diffusion. Shift from abrasion mechanism to adhesion or even diffusion could result from high tool-chip interface temperature [22]. In the present work owing to machining in wet condition and cutting with moderate spindle speed, adhesion and diffusion wear is not taken into consideration. According to the results of the second machining stage shown in Figure 9, maximum wear refers to dry condition, SAE10 oil, and vegetable oil respectively. Vegetable and SAE10 oils could better lubricate the cutting zone and lessen direct contact of rake surface of cutting tool and workpiece. The workpiece surface rubs off the tool material and causes tool wear. This is clear for dry cutting.
During milling in wet conditions, tool works in lower temperature than in dry condition so lower friction coefficient and tougher tool material are the consequences. Additionally, a thin layer of fluid that exists between tool and workpiece prevents metal to metal contact, which could reduce frictional forces more and more. Therefore, less tool wear could be observed when applying cutting fluid. In dry cutting, tool material would be affected from produced heat and causes tool softening so this can lead to higher tool wear. Figure 9 displays that coolant preserves the rigidity of tools and allows them to work in smooth circumstance.

\section{Conclusion}

This study involved different lubrication environments on milling a St60 block. The aim was to estimate the effect of two types of cutting oil (i.e. sunflower oil and SAE10 oil) as well as various concentrations of them on machining performance. Two machining stages were planned. At the first one, three distinct combinations of cutting speed and depth of cut were set. The concentration of cutting fluids resulted to the best surface roughness was selected for the second machining stage to survey the tool wear. From the total results it can be concluded that the type and concentration of cutting fluids both affect directly on efficiency of machining operation. Although, it is difficult to have an absolute conclusion but lowering the oil content in the cutting fluids could better machining performance. Based on the results, a development potential of dry machining is observed. In this case, flank wear increased; however, it was shown that in the absence of any lubricant, surface finish and cutting power could be improved in high spindle speed machining. In milling at a low spindle speed, it is better to use a high viscous fluid like SAE10 that resulted in a good surface finish and reasonable power consumption and tool wear. Vegetable oil displayed acceptable lubrication ability. Lower consuming power in all cutting condition and minimum tool wear was produced in this lubrication environment.

Result of this survey can be suitable for machine tool operators to find the optimum situation which has the best surface roughness and tool life according to the machining speed, depth of cut and type of cutting fluid. Studying several work materials with different temperatures (pre-cooled and pre-heated) and variety of tools could be the future scope of this work to earn more precise and functional outcomes.

Acknowledgements. The authors wish to thank Mohsen Poorfallah, Hamid Baseri and Saeed Shiri for their support that is worthy of mention and respect. Also, we would like to thank the Babol Noshirvani University of Technology for supplying facilities to ease the way to the project. 


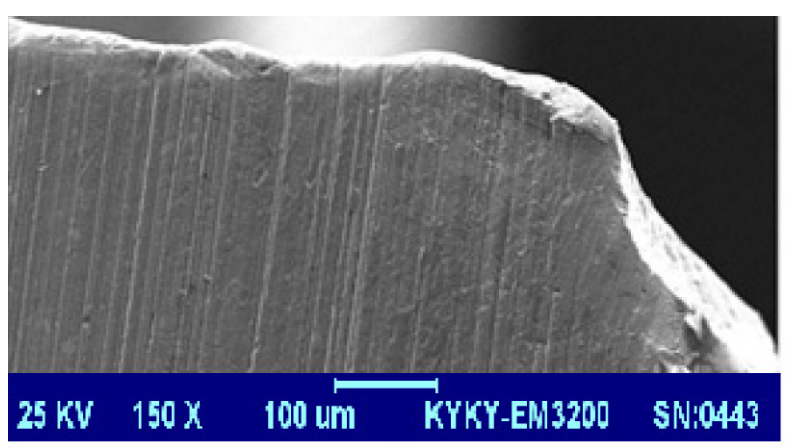

(a)

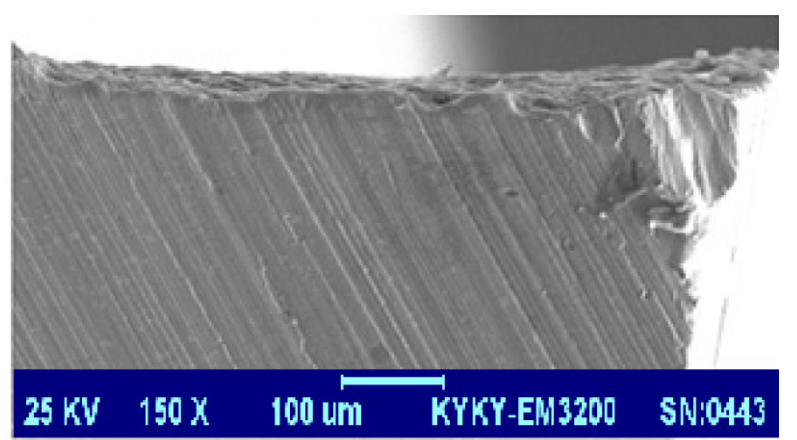

(b)

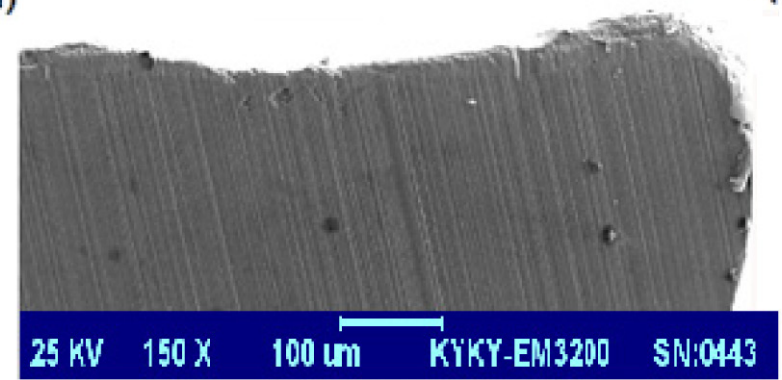

(c)

Fig. 9. Amount of tool flank wear in SEM observations (150 X): (a) Dry, (b) SAE10 oil and (c) and vegetable oil.

\section{References}

[1] J.P. Byers, Metalworking fluids CrC Press, 2006

[2] R. Neugebauer, W. Drossel, R. Wertheim, C. Hochmuth, M. Dix, Resource and Energy Efficiency in Machining Using High-Performance and Hybrid Processes, Procedia CIRP 1 (2012) 3-16

[3] Y. Shashidhara, S. Jayaram, Vegetable oils as a potential cutting fluid - an evolution, Tribol. Int. 43 (2010) 10731081

[4] M.A. Xavior, M. Adithan, Determining the influence of cutting fluids on tool wear and surface roughness during turning of AISI 304 austenitic stainless steel, J. Mater. Process. Technol. 209 (2009) 900-909

[5] E. Kuram, B. Simsek, B. Ozcelik, E. Demirbas, S. Askin, Optimization of the cutting fluids and parameters using Taguchi and ANOVA in milling, in Proceedings of the World Congress on Engineering, 2010

[6] N. Dhar, S. Paul, A. Chattopadhyay, The influence of cryogenic cooling on tool wear, dimensional accuracy and surface finish in turning AISI 1040 and E4340C steels, Wear 249 (2001) 932-942

[7] Y.K. Hwang, C.M. Lee, Surface roughness and cutting force prediction in MQL and wet turning process of AISI 1045 using design of experiments, J. Mech. Sci. Technol. 24 (2010) 1669-1677

[8] N. Suresh Kumar Reddy, P. Venkateswara Rao, Experimental investigation to study the effect of solid lubricants on cutting forces and surface quality in end milling, Int. J. Machine Tools Manuf. 46 (2006) 189-198

[9] P. Vamsi Krishna, D. Nageswara Rao, Performance evaluation of solid lubricants in terms of machining parameters in turning, Int. J. Machine Tools Manuf. 48 (2008) $1131-1137$
[10] V. Vasu, G.P.K. Reddy, Effect of minimum quantity lubrication with $\mathrm{Al} 2 \mathrm{O} 3$ nanoparticles on surface roughness, tool wear and temperature dissipation in machining Inconel 600 alloy, Proc. Instit. Mech. Eng., Part N 225 (2011) 3-16

[11] R.S. Gunerkar, P. Kuppan, Experimental Investigation of Vegetable Oil Based Cutting Fluid During Turning of SS316L, Int. J. Mech. Eng. Robotics (IJMER) 1 (2013) $46-52$

[12] N. Fox, G. Stachowiak, Vegetable oil-based lubricants a review of oxidation, Tribol. Int. 40 (2007) 1035-1046

[13] M. Khan, M. Mithu, N. Dhar, Effects of minimum quantity lubrication on turning AISI 9310 alloy steel using vegetable oil-based cutting fluid, J. Mater. Process. Technol. 209 (2009) 5573-5583

[14] M.T. Siniawski, N. Saniei, B. Adhikari, L.A. Doezema, Influence of fatty acid composition on the tribological performance of two vegetable based lubricants, J. Synthetic Lubrication 24 (2007) 101-110

[15] M.H. Cetin, B. Ozcelik, E. Kuram, E. Demirbas, Evaluation of vegetable based cutting fluids with extreme pressure and cutting parameters in turning of AISI 304L by Taguchi method, J. Cleaner Prod. 19 (2011) 2049 2056

[16] E. Kuram, Babur Ozcelik, M. Huseyin Cetin, Erhan Demirbas, S. Askin., Effects of blended vegetable-based cutting fluids with extreme pressure on tool wear and force components in turning of Al 7075-T6, Lubrication Science 25 (2013) 39-52 
[17] V.S. Sharma, M. Dogra, N.M. Suri, Cooling techniques for improved productivity in turning, Int. J. Machine Tools Manuf. 49 (2009) 435-453

[18] L. Yan, S. Yuan, Q. Liu, Influence of minimum quantity lubrication parameters on tool wear and surface roughness in milling of forged steel, Chinese J. Mech. Eng. 25 (2012) 419-429

[19] Y Shokoohi, E. Khosrojerdi, B.h.R. Shiadhi, Machining and ecological effects of a new developed cutting fluid in combination with different cooling techniques on turning operation, J. Cleaner Prod. 94 (2015) 330-339
[20] T.L. Ginta, A. Amin, M.A. Lajis, A. Karim, C. Daud, M. Radzi, Improved tool life in end milling Ti-6A1-4V through workpiece preheating, Eur. J. Sci. Res. 27 (2009) 384-391

[21] K. Weinert, I. Inasaki, J.W. Sutherland, T. Wakabayashi, Dry Machining and Minimum Quantity Lubrication, CIRP Annals - Manufact. Technol. 53 (2004) 511-537

[22] M. Nouari, G. List, F. Girot, D. Coupard, Experimental analysis and optimisation of tool wear in dry machining of aluminium alloys, Wear 255 (2003) 1359-1368 